\title{
Microstructure and Mechanical Properties of $\beta$-SiAlON Ceramics Fabricated Using Self-Propagating High-Temperature Synthesized $\beta$-SiAlON Powder
}

\author{
Min-Sung Kim****, Shin-Il Go G******, Jin-Myung Kim ${ }^{* * *}$, Young-Jo Park***,, \\ Ha-Neul Kim***, Jae-Woong Ko*** and Jon-Do Yun* \\ *Advanced Engineering Division, Kyungnam University, Changwon 51767, Korea \\ **Powder and Ceramics Division, Korea Institute of Materials Science, Changwon 51767, Korea \\ ***Materials Science and Engineering, Pusan National University, Pusan 46241, Korea
}

(Received April 25, 2017; Revised June 23, 2017; Accepted June 23, 2017)

\begin{abstract}
$\beta$-SiAlON, based on its high fracture toughness, good strength and low abrasion resistance, has been adopted in several industrial fields such as bearings, turbine blades and non-ferrous metal refractories. In general, $\beta$-SiAlON is fabricated by reactive sintering using expensive $\mathrm{Si}_{3} \mathrm{~N}_{4}$ and AlN as starting materials. On the other hand, in this study, a cheaper $\beta$-SiAlON starting powder synthesized by SHS was employed to improve price competitiveness compared to that of the reactive sintering process. $\beta$ SiAlON ceramics with various content of the sintering additive $\mathrm{Y}_{2} \mathrm{O}_{3}$ up to $7 \mathrm{wt} \%$ were fabricated by conventional pressureless sintering at $1800^{\circ} \mathrm{C}$ for 2 to $8 \mathrm{~h}$ under $\mathrm{N}_{2}$ pressure of $0.1 \mathrm{MPa}$. The specimen with 3 wt $\% \mathrm{Y}_{2} \mathrm{O}_{3}$ exhibited the best mechanical properties: hardness of $14 \mathrm{GPa}$, biaxial strength of $830 \mathrm{MPa}$, fracture toughness of $5 \mathrm{MPa} \cdot \mathrm{m}^{1 / 2}$ and wear rate of about $3 \times 10^{-6}$ $\mathrm{mm}^{3} / \mathrm{N} \cdot \mathrm{m}$.
\end{abstract}

Key words : SiAlON, SHS, Gas Pressure Sintering, Roll Bearing, Wear Resistance

\section{Introduction}

$\beta$ SiAlON $\left(\mathrm{Si}_{6-\mathrm{z}} \mathrm{Al}_{\mathrm{z}} \mathrm{O}_{\mathrm{z}} \mathrm{N}_{8-\mathrm{z}}\right)$, a solid solution of silicon nitride $\left(\mathrm{Si}_{3} \mathrm{~N}_{4}\right)$ showing excellent high-temperature strength, thermal shock resistance, oxidation resistance, and chemical stability, is applied to high-performance bearings, turbine blades, and non-ferrous molten metal refractories, because the volumetric ratio of the intergranular amorphous phase remaining after sintering is smaller than that of silicon nitride. ${ }^{1-2)}$ In $\beta$-SiAlON, with an increase of temperature $\left(1400\right.$ to $\left.1600^{\circ} \mathrm{C}\right)$ following the conversion of the raw materials into a eutectic liquid, the low-temperature phase, $\alpha-\mathrm{Si}_{3} \mathrm{~N}_{4}$, melts into the liquid. $\beta-\mathrm{SiAlON}$ is then precipitated as a stable phase to accomplish densification through a transient liquid sintering mechanism, where crystallization occurs, theoretically, without a residual liquid. ${ }^{3,4)}$ Generally, however, a certain amount of a sintering aid is required for high-density sintering of $\beta$-SiAlON, and the presence of a residual amorphous phase is unavoidable in the sintered body. Nevertheless, the high-temperature properties of the $\beta$-SiAlON-based sintered body are superior to those of the silicon nitride, because the amount of the added and/or remnant sintering aid is smaller in the $\beta$-SiAlON-based sintered body.

\footnotetext{
Corresponding author: Young-Jo Park

E-mail : yjpark87@kims.re.kr

Tel : +82-55-280-3356 Fax : +82-55-280-3392
}

$\beta$-SiAlON, whose eutectic liquid contributing to densification is consumed by crystallization, is known as a poor sinterable ceramic in comparison with silicon nitride. Methods of obtaining a high-density sintered body include pressureless sintering with the addition of an excessive amount of a sintering aid $^{5)}$ and press sintering with the addition of a minimum amount of a sintering aid. Examples of the latter are hot press (HP) sintering, hot isostatic press (HIP) sintering, and spark plasma sintering (SPS). ${ }^{6}$ )

$\beta$-SiAlON is commonly prepared by reaction sintering where the synthesis from the starting materials, such as $\mathrm{Si}_{3} \mathrm{~N}_{4}, \mathrm{AlN}$, and $\mathrm{Al}_{2} \mathrm{O}_{3}$, occurs simultaneously with the densification of the SiAlON phase. ${ }^{7)}$ However, since the nonoxide ceramics, e.g., $\mathrm{Si}_{3} \mathrm{~N}_{4}$ or $\mathrm{AlN}$, are expensive, the unit price of the sintered parts manufactured by using these materials is very high. ${ }^{8}$ In the present study, to enhance the price competitiveness of $\beta$-SiAlON parts, a $\beta$-SiAlON sintered body was prepared by a normal sintering process, not reaction sintering, by using a less expensive $\beta$-SiAlON powder manufactured by Self-propagating High-temperature Synthesis (SHS). SHS, which is a method of synthesizing a powder by using the heat of reaction released from the process of generating products through the reactions between raw materials, may enable low-price powder synthesis because the synthesis time is short and the required equipment is simple as the reactions are propagated and continued within the powder batch spontaneously without external energy. ${ }^{9)}$ In the present study, pressureless sintering was 
performed in a nitrogen atmosphere by adding 0 to $7 \mathrm{wt} \%$ of $\mathrm{Y}_{2} \mathrm{O}_{3}$ as a sintering aid, and the properties of the resulting sintered body were compared with those of the sintered body produced by the costly reaction sintering.

\section{Experimental Procedure}

The starting raw materials were commercially available SHS $\beta$-SiAlON powder (Combustion Synthesis Co., Ltd, Hokkaido, Japan), represented by the chemical composition formula of $\mathrm{Si}_{6-\mathrm{z}} \mathrm{Al}_{\mathrm{z}} \mathrm{O}_{\mathrm{z}} \mathrm{N}_{8-\mathrm{z}}\left(\mathrm{z}=0.5\right.$ ), and $\mathrm{Y}_{2} \mathrm{O}_{3}$ (grade $\mathrm{C}$, H.C. Starck, Goslar, Germany) used as a sintering aid. The $\beta$ SiAlON powder was calcinated in air at $1000^{\circ} \mathrm{C}$ for $2 \mathrm{~h}$, but weight loss due to residual organic substances was not detected. Wet ball-milling was performed after adding 0 wt $\%, 1 \mathrm{wt} \%, 3 \mathrm{wt} \%, 5 \mathrm{wt} \%$, and $7 \mathrm{wt} \%$ of $\mathrm{Y}_{2} \mathrm{O}_{3}$ to the $\beta$-SiAION powder (Table 1). The ball-milling was performed for $24 \mathrm{~h}$ at $200 \mathrm{rpm}$ for $24 \mathrm{~h}$ by using an anhydrous alcohol solvent, a zirconia container, and $\mathrm{Si}_{3} \mathrm{~N}_{4}$ balls having a diameter of $5 \mathrm{~mm}$. The mixed powder was dried by using a rotary evaporator and then sieved by using a 230 -mesh sieve. Uniaxial press molding was performed by weighing $1.2 \mathrm{~g}$ of the mixed powder and using a $15 \mathrm{~mm}$ round mold. Cold isostatic pressing at $200 \mathrm{MPa}$ was then performed to prepare a green body having a diameter of about $14 \mathrm{~mm}$ and a height of about $4.5 \mathrm{~mm}$. A graphite crucible was filled with an atmospheric powder $\left(\mathrm{Si}_{3} \mathrm{~N}_{4}: \mathrm{BN}=1: 1\right)$ to which the molded body was buried. The crucible was then charged to a graphite-heated furnace for sintering at $1800^{\circ} \mathrm{C}$ for $2 \mathrm{~h}$ (T18t2h) or for $4 \mathrm{~h}(\mathrm{~T} 18 \mathrm{t} 4 \mathrm{~h})$ in an $0.1 \mathrm{MPa}$ nitrogen atmosphere. The former number in each of the experiment denotations refers to the sintering temperature, while the latter number refers to the duration. After the sintering, the density of individual specimens was measured by Archimedes method. In addition, a phase analysis of the mixed powder and the sintered specimens was performed through X-ray diffraction (D/ MAX 2500VL, Rigaku, Japan). The specimens were ground to be $1.2 \mathrm{~mm}$ thick, and both surfaces were mirror-polished by using $1 \mu \mathrm{m}$ diamond slurry to measure the biaxial flexural strength according to the ISO 6872 method. In addition, according to the method of ISO 6507-1, the Vickers hardness was measured by applying $1 \mathrm{~kg}$ of load (FM-700A, Future Tech, Japan) and the fracture toughness was measured by applying $20 \mathrm{~kg}$ of load (HV-112, Akashi, Japan). The average hardness and fracture toughness measurement values, obtained by performing the tests 7 and 9

Table 1. Designation of Sample Name and Sintering Condition

\begin{tabular}{cccc}
\hline Sample & Sintering Add & \multicolumn{2}{c}{ Sintering Condition } \\
\hline $0 \mathrm{Y}$ & $0 \mathrm{wt} \% \mathrm{Y}_{2} \mathrm{O}_{3}$ & \multirow{2}{*}{$\mathrm{T} 18 \mathrm{t} 2 \mathrm{~h}$} & $1800^{\circ} \mathrm{C}$, \\
$1 \mathrm{Y}$ & $1 \mathrm{wt} \% \mathrm{Y}_{2} \mathrm{O}_{3}$ & & \\
$3 \mathrm{Y}$ & $3 \mathrm{wt} \% \mathrm{Y}_{2} \mathrm{O}_{3}$ & & \\
$5 \mathrm{Y}$ & $5 \mathrm{wt} \% \mathrm{Y}_{2} \mathrm{O}_{3}$ & $\mathrm{~T} 18 \mathrm{t} 4 \mathrm{~h}$ & $1800^{\circ} \mathrm{C}$, \\
$7 \mathrm{Y}$ & $7 \mathrm{wt} \% \mathrm{Y}_{2} \mathrm{O}_{3}$ & & $4 \mathrm{~h}$ holding \\
\hline
\end{tabular}

times, respectively, were used for the analysis, and the fracture toughness was calculated by using the Niihara equation. $^{10)}$ In addition, the wear resistance of the T18t4h sintered body was measured by the ball-on-disk method (ASTM G133-05) at room temperature. The counterpart ball made of bearing-class silicon nitride was used in the test where the specimens were worn under a load of $5 \mathrm{~N}$, in a wearing radius of $3 \mathrm{~mm}$ at a rate of $1000 \mathrm{rpm}$ for $30 \mathrm{~min}$ utes, and then the amount of wear was analyzed by using an optical profiler (Tencor, P-1, NJ, USA). The polished sintered body was plasma-etched, and was then subjected to a micro-structure analysis using a scanning electron microscope (SEM, JSM-5800, Jeol, Japan) and X-ray spectroscopy using an energy dispersive spectrometer (EDS).

\section{Results and Discussion}

Figures 1 and 2 show SEM images and the particle size analysis results of the $\beta$-SiAlON powder synthesized by SHS. The analysis of the $\beta$-SiAlON powder showed that the powder had an angular shape due to the pulverization following the synthesis and a particle diameter of about $1 \mu \mathrm{m}$ $\left(D_{50}=1.0 \mu \mathrm{m}\right)$. Fig. 3 shows the relative density (\%TD) of

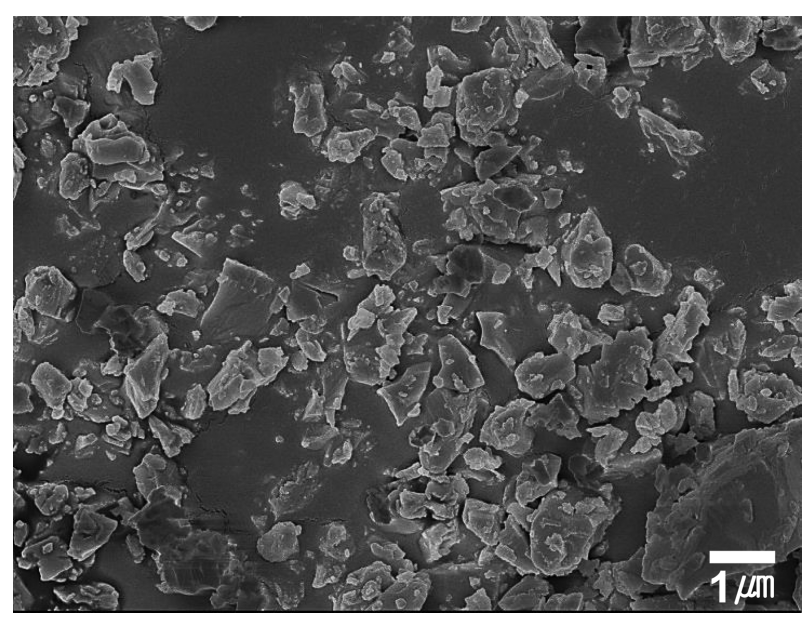

Fig. 1. SEM image of $\beta$-SiAlON raw powder by SHS.

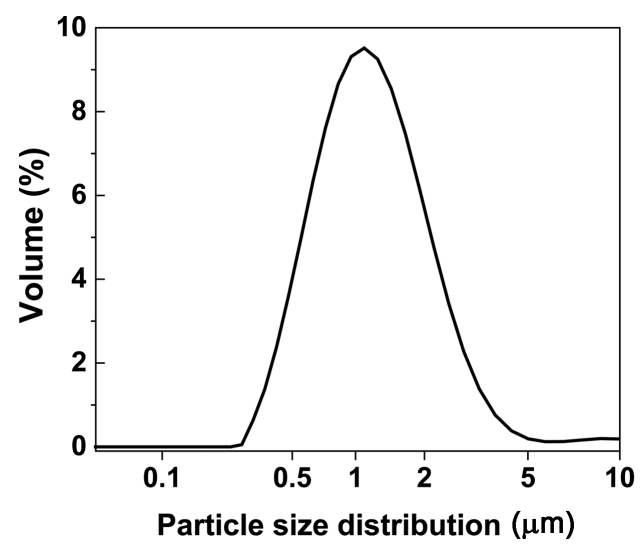

Fig. 2. Particle size distribution of $\beta$-SiAlON raw powder. 


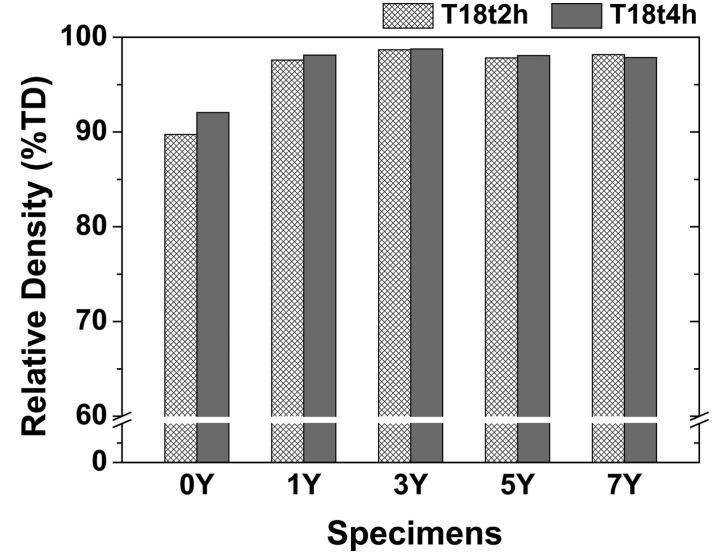

Fig. 3. Measurement of relative density of specimens sintered at $1800^{\circ} \mathrm{C}$ for $2,4 \mathrm{~h}$.

the sintered body depending on the amount of the added sintering aid and the sintering conditions (T18t2h and $\mathrm{T} 18 \mathrm{t} 4 \mathrm{~h}$ ). The average relative density of the specimens prepared by adding a sintering aid was over $98 \%$, which was higher than that of the specimens without an sintering aid (below 92\%). The densification and the phase transition rate are known to be dependent on the type and amount of the added sintering aid. ${ }^{11)}$ In the present study, a sintered body having an excellent sintering density was obtained when $\mathrm{Y}_{2} \mathrm{O}_{3}$ was added at $3 \mathrm{wt} \%$. On the other hand, the difference in the relative density depending on the sintering duration was negligible, indicating that the densification was completed by the sintering for $2 \mathrm{~h}$.

Figure 4(a) shows the XRD patterns of the $\beta$-SiAlON powder and the mixed powder. A powder synthesized by SHS is generally known to contain unreacted reactants even after the reaction process. ${ }^{12)}$ The powder used in the present study was identified as a single $\beta$-SiAlON phase, which is presumed to be evidence of a purification process that followed the SHS synthesis. Fig. 4(b) shows the XRD pattern of the specimen prepared under the T18t4h condition. A secondary phase of $\mathrm{Y}_{2} \mathrm{SiAlO}_{5} \mathrm{~N}$ was detected in the specimen prepared by adding the sintering aid at $5 \mathrm{wt} \%$ or higher.
Table 2. Chemical Composition of $\mathrm{Si}$ and Al Ratio by EDS. Specimens were Sintered under T18t4h Condition

\begin{tabular}{ccccc}
\hline \multirow{2}{*}{ Sample } & \multicolumn{3}{c}{ Chemical Composition (at\%) } & \multirow{2}{*}{ z value } \\
\cline { 2 - 4 } & $\mathrm{Si}$ & $\mathrm{Al}$ & $\mathrm{Si}: \mathrm{Al}$ & \\
\hline $0 \mathrm{Y}$ & 32.89 & 3.98 & $8.26: 1$ & 0.65 \\
$\mathrm{TY}$ & 27.92 & 3.48 & $8.02: 1$ & 0.67 \\
$3 \mathrm{Y}$ & 28.23 & 3.33 & $8.48: 1$ & 0.63 \\
$5 \mathrm{Y}$ & 28.07 & 3.15 & $8.9: 1$ & 0.61 \\
$7 \mathrm{Y}$ & 27.81 & 3.09 & $9.0: 1$ & 0.6 \\
\hline
\end{tabular}

The secondary phase was particularly distinctive in the $7 \mathrm{Y}$ specimen, indicating that the secondary phase may be generated when a sintering aid is added excessively, as described above. Table 2 shows the EDS analysis results of the sintered body prepared under the $\mathrm{T} 18 \mathrm{t} 4 \mathrm{~h}$ condition. The $\mathrm{z}$-values of the specimens, representing the atomic ratio of $\mathrm{Si}$ : $\mathrm{Al}$, were $0.65,0.67,0.63,0.61$, and 0.6 , respectively, which were slightly higher than the substitution ratio of the purchased powder (0.5). The increase in the z-value was likely due to the increase of the stable phase of $\beta$-SiAlON as it was precipitated during the grain growth by the 'dissolution-reprecipitation' mechanism after a eutectic liquid was produced from the starting material, SiAlON, and the sintering aid, $\mathrm{Y}_{2} \mathrm{O}_{3}$. At the same time, the $\mathrm{z}$-value decreased as the amount of the added sintering aid increased, possibly because the amount of substituted $\mathrm{Al}$ decreased due to the generation of a secondary phase including $\mathrm{Al}$.

Figures 5(a) to 5(e) show the microstructure of the T18t4h sintered body observed in a secondary electron (SE) mode depending on the amount of the sintering aid. As the amount of the sintering aid increased, the size of the coarse particles remained unchanged but the size of the smaller particles decreased in a particle growth pattern. The crosssection of the coarse particles was close to hexagonal, and their size was about $3 \mu \mathrm{m}$. One notable finding in the present study is that the particle aspect ratio of the sintered body of the present study prepared by using the $\beta$-SiAlON powder as the starting material was smaller than that of
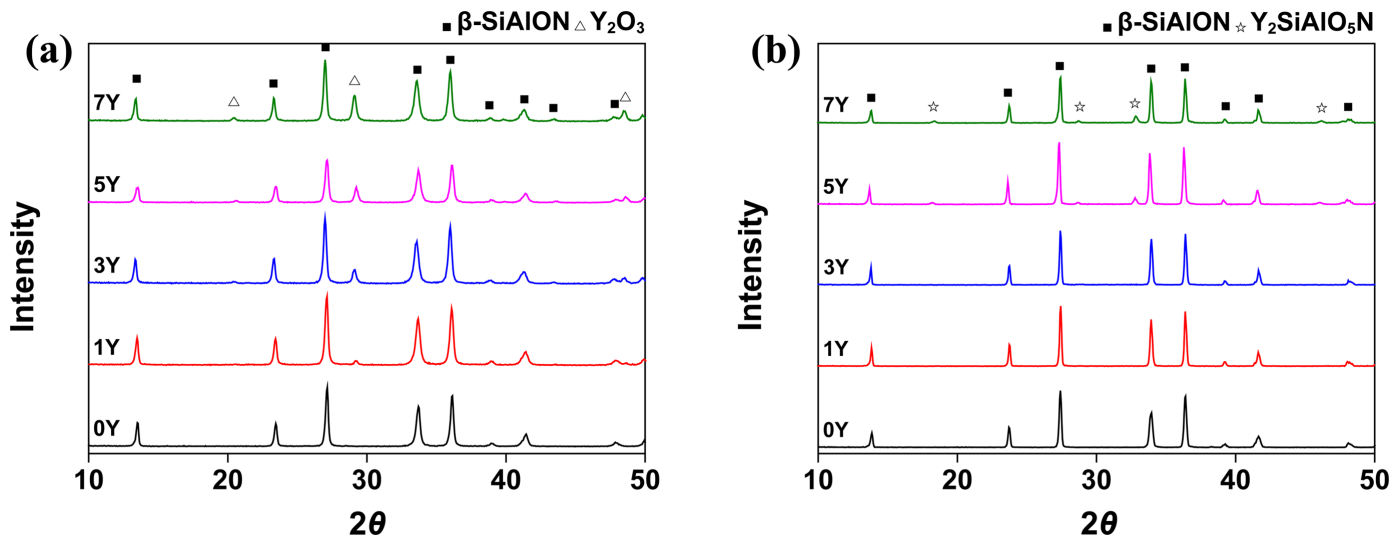

Fig. 4. XRD patterns of (a) $\beta$-SiAlON raw powder and $\mathrm{Y}_{2} \mathrm{O}_{3}$ mixed powders and (b) specimens sintered under T18t4h condition. 

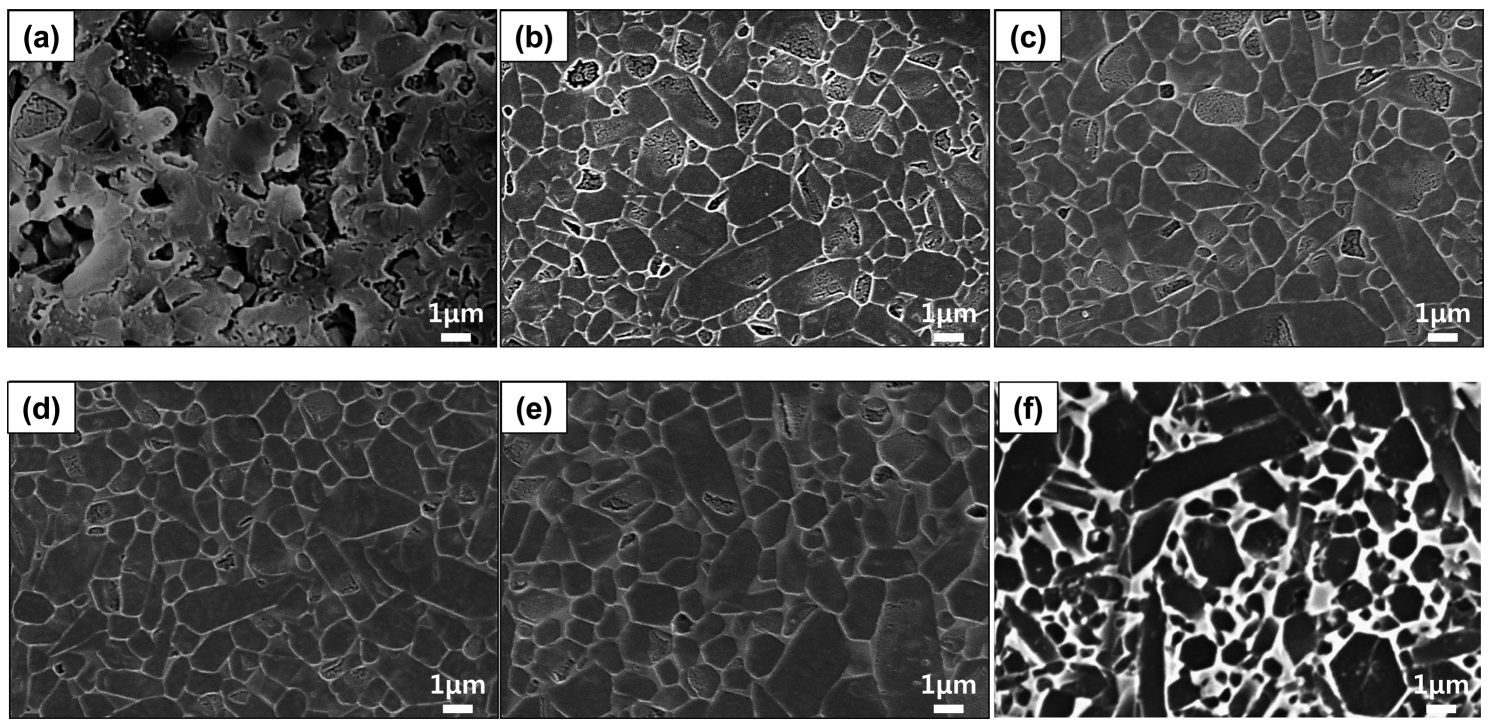

Fig. 5. SEM images of conventional pressureless sintered specimens under T18t4h condition with $\mathrm{Y}_{2} \mathrm{O}_{3}$ addition of: (a) $0 \mathrm{Y}$, (b) $1 \mathrm{Y}$, (c) $3 \mathrm{Y}$, (d) $5 \mathrm{Y}$ and (e) $7 \mathrm{Y}$ and (f) reactive sintered specimen.

the sintered body prepared by reaction sintering. Fig. 5(f) shows the microstructure of the specimen prepared by reaction sintering in our previous study. ${ }^{13)}$ In the reaction sintering where $\alpha-\mathrm{Si}_{3} \mathrm{~N}_{4}$ is used as the starting material, a microstructure with a high aspect ratio may be obtained through the phase transition and particle growth by the dissolutionreprecipitation mechanism. However, in the present study where $\beta$-SiAlON was used as the starting material, abnormal growth of the particles leading to a large aspect ratio did not occur. Figs. 6(a) to 6(e) show the microstructure of the sintered body observed in a back-scattered electron (BSE) mode, indicating that the volume fraction of the intergranular amorphous phase increased as the amount of the added $\mathrm{Y}_{2} \mathrm{O}_{3}$ increased. Since the generation of an excessive intergranular amorphous phase decreases high-tempera- ture mechanical properties and strength, ${ }^{14)}$ a smaller amount of an amorphous phase is preferable at a level that enables densification.

Figure 7 shows the biaxial flexural strength of the sintered body, indicating that the strength was dependent on the amount of the sintering aid. The optimal flexural strength $(830 \mathrm{MPa})$ was found in the $5 \mathrm{Y}$ specimen. However, the flexural strength drastically decreased in the $7 \mathrm{Y}$ specimen containing $7 \mathrm{wt} \%$ of the sintering aid. This suggests that the generation of a large amount of a secondary phase having weaker mechanical properties may have decreased the strength.

Figure 8 shows the hardness and fracture toughness of the $\mathrm{T} 18 \mathrm{t} 2 \mathrm{~h}$ and $\mathrm{T} 18 \mathrm{t} 4 \mathrm{~h}$ specimens depending on the sintering time and the amount of the sintering aid. The fracture
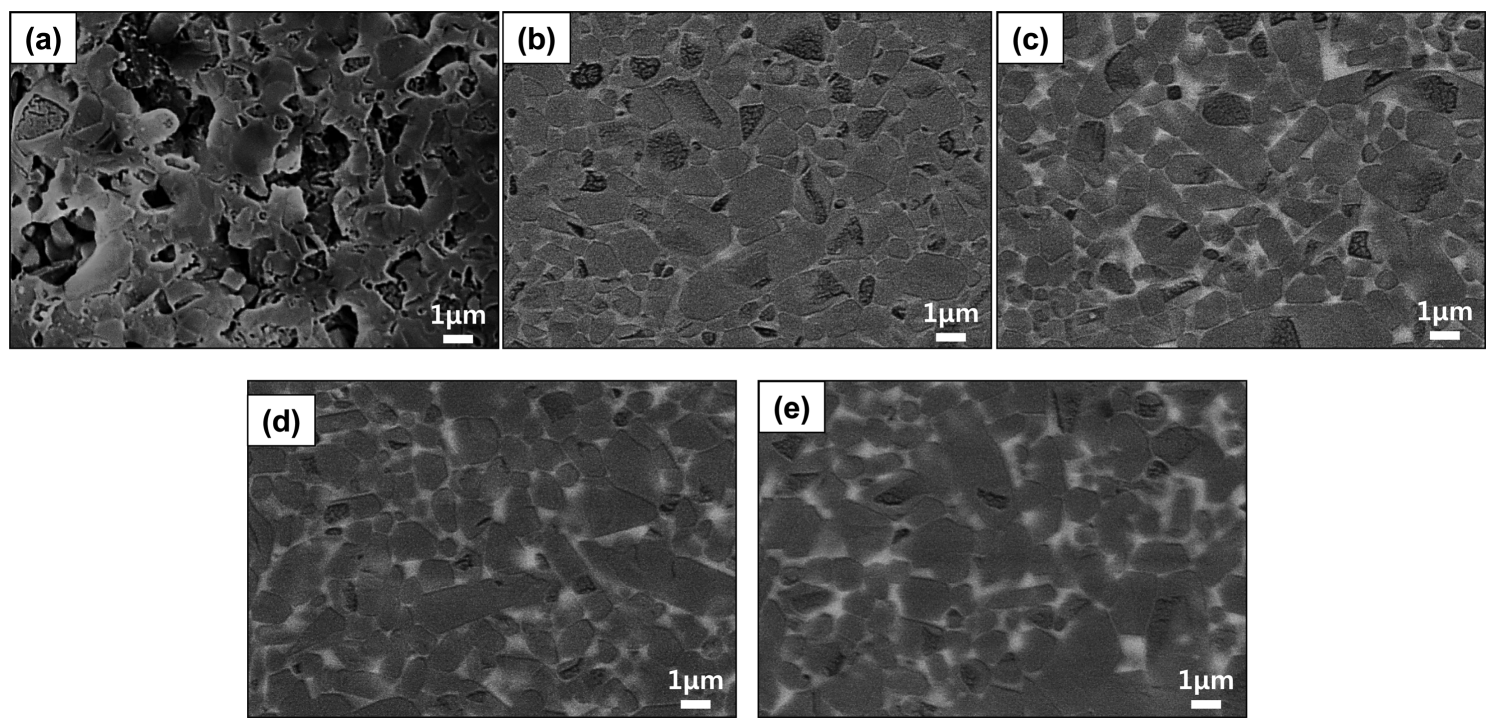

Fig. 6. BSE images of specimens with $\mathrm{Y}_{2} \mathrm{O}_{3}$ addition sintered under T18t4h condition. (a) $0 \mathrm{Y}$, (b) $1 \mathrm{Y}$, (c) $3 \mathrm{Y}$, (d) $5 \mathrm{Y}$ and (e) $7 \mathrm{Y}$. 


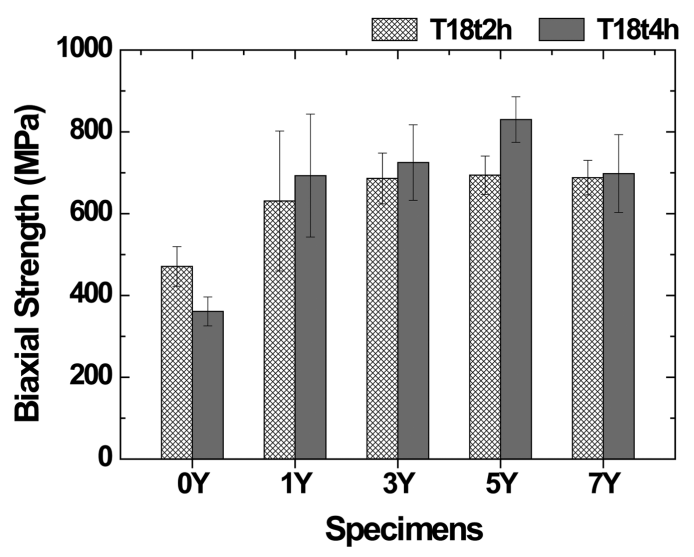

Fig. 7. Biaxial strength of specimens sintered under T18t2h, T18t4h conditions.

toughness was calculated by using the following Niihara equation:

$$
K_{I C}=0.0309\left(\frac{E}{H_{V}}\right)^{0.4} \cdot\left(\frac{P}{C^{1.5}}\right)
$$

where $\mathrm{K}_{\mathrm{IC}}$ denotes the fracture toughness, $\mathrm{E}$ the elastic modulus, $\mathrm{H}_{\mathrm{V}}$ the hardness, $\mathrm{P}$ the indentation load, and $\mathrm{C}$ the crack length. The hardness and the toughness of the $\mathrm{T} 18 \mathrm{t} 2 \mathrm{~h}$ specimen were higher than those of the T18t4h specimen, which indicates that excellent mechanical properties may be obtained by sintering for just $2 \mathrm{~h}$, as described above. The hardness of all the specimens, except the $0 \mathrm{Y}$ specimen, was over $14 \mathrm{GPa}$, and the hardness slightly decreased as the amount of the sintering aid increased. The fracture toughness of the T18t2h specimens was equal to or higher than $5 \mathrm{MPa} \cdot \mathrm{m}^{1 / 2}$, but it drastically decreased as the amount of the sintering aid increased. This may be because the volume fraction of the intergranular amorphous phase, having a lower hardness, increased and a secondary precipitant was generated when an excessive amount of the sintering aid was added. On the other hand, the strength and the toughness of the sintered body prepared in the present study were lower than those of the abovementioned sintered body prepared by the conventional reaction sintering (strength: $1050 \mathrm{MPa}$; toughness: $6.08 \mathrm{MPa} \cdot \mathrm{m}^{1 / 2}$ ). ${ }^{13)}$ The decrease of the strength in comparison with the sintered body prepared by the reaction sintering may be because of the increase of the average particle size, and the decrease of the toughness may be due to the decrease of the particle aspect ratio. ${ }^{15)}$

Figure 9(a) shows the coefficient of fraction (COF) of the sintered body. The COF remained constant in a range from 0.4 to 0.6 regardless of the amount of the added $\mathrm{Y}_{2} \mathrm{O}_{3}$. However, the $0 Y$ specimen having a low density was rapidly worn as the number of cycles increased. Fig. 9(b) shows the
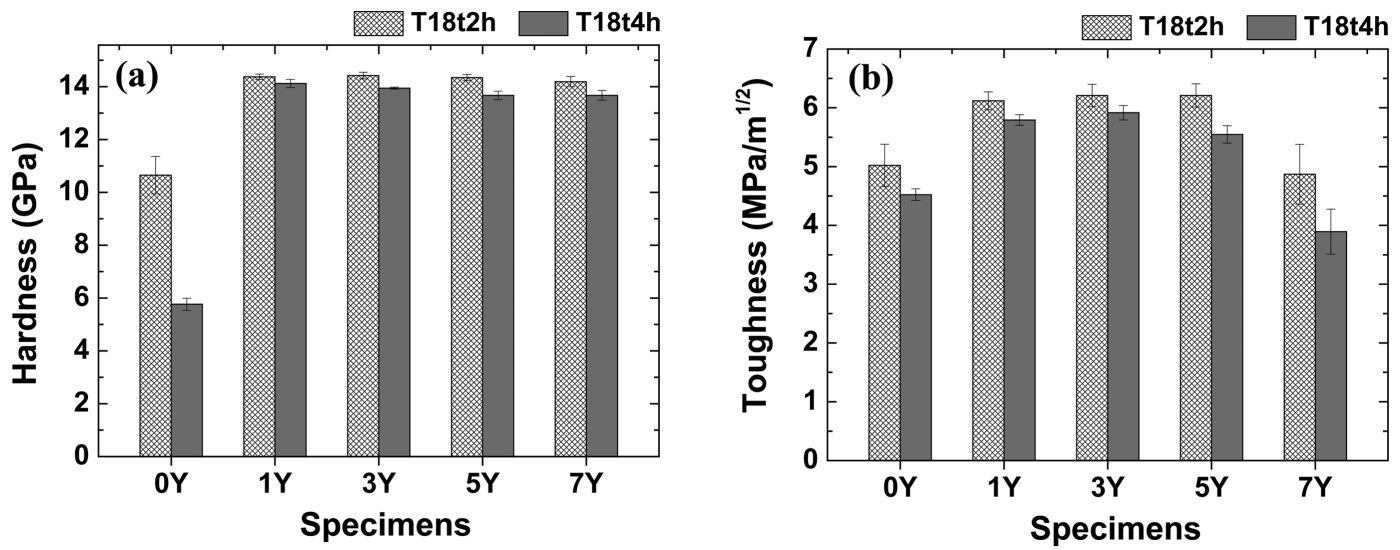

Fig. 8. Measurement of (a) hardness and (b) fracture toughness of specimens sintered under T18t2h and T18t4h conditions.
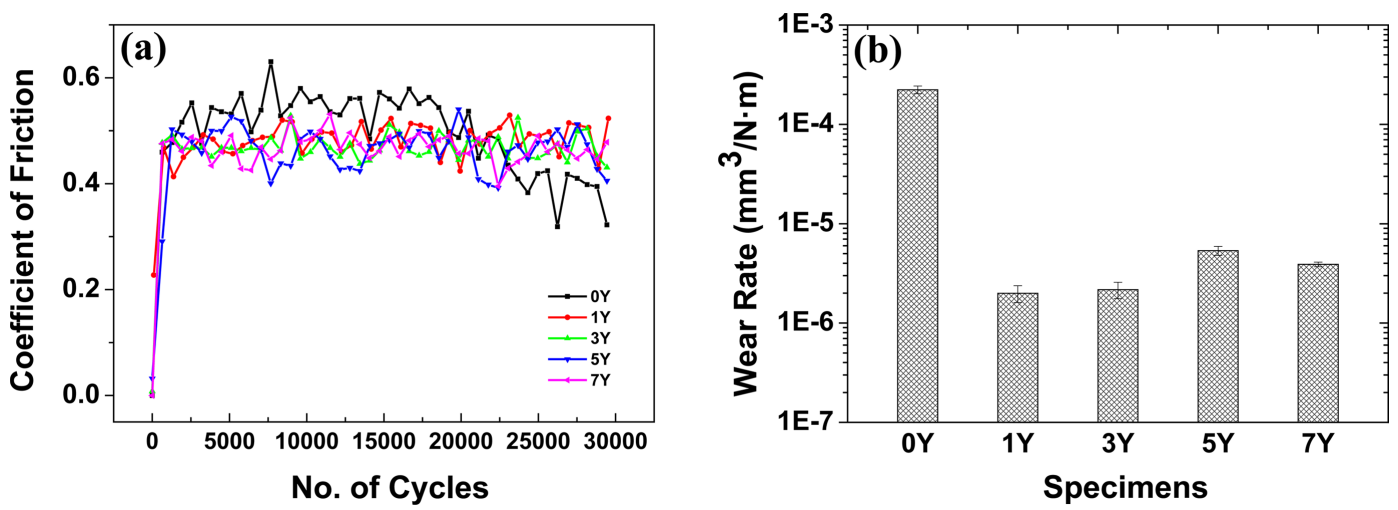

Fig. 9. Measurements of T18t4h specimens of (a) coefficent of friction and (b) wear rate. 
wear rate representing the amount of wear divided by the load and the wear distance. An average wear resistance of 3 $\times 10^{-6} \mathrm{~mm}^{3} / \mathrm{N} \cdot \mathrm{m}$ was accomplished in all the specimens, except the $0 \mathrm{Y}$ specimen. As the amount of the sintering aid increased, the wear resistance decreased but within the same order of magnitude. However, since the addition of an excessive amount of the sintering aid may cause the formation of a glass-like phase at the triple point as well as detachment due to the increased volume fraction and wear focused on the detached region, an optimal amount of $\mathrm{Y}_{2} \mathrm{O}_{3}$ from $1 \mathrm{wt} \%$ to $3 \mathrm{wt} \%$ may be appropriately added to improve the wear resistance.

\section{Conclusions}

In the present study, a $\beta$-SiAlON sintered body was prepared for the first time in Korea by a normal sintering process, not reaction sintering, by using a $\beta$-SiAlON powder synthesized by SHS. The following findings were made through this study. First, a dense sintered body having a relative density of over $98 \%$ was obtained under pressureless sintering conditions at $1800^{\circ} \mathrm{C}$ for $2 \mathrm{~h}$. Second, since the powder prepared by SHS already had the $\beta$-SiAlON phase, the aspect ratio of the grains obtained by the normal sintering was smaller than that of the grains prepared by the conventional reaction sintering where the synthesis starts with an $\alpha$ phase to obtain a $\beta$ phase. Third, the addition of an excessive amount of $\mathrm{Y}_{2} \mathrm{O}_{3}$, a sintering aid, lowered the mechanical properties of the sintered body because of the generation of an intergranular amorphous phase and a secondary phase, and the appropriate content of the $\mathrm{Y}_{2} \mathrm{O}_{3}$ addition was found to be $3 \mathrm{wt} \%$ to $5 \mathrm{wt} \%$. Fourth, although less expensive $\beta$-SiAlON powder was used, various mechanical properties of the sintered body, except the strength value, were similar to those of the expensive sintered body prepared by conventional reaction sintering. The results of the present study may be applied to realize low-cost SiAlON ceramics having excellent price competitiveness, and the sintered body prepared in the present study may be applied to various mechanical parts.

\section{Acknowledgments}

The present study was a research project of the Advanced Technology Center (ATC) supported by the Ministry of Trade, Industry and Energy (Grant Number: 10052448).

\section{REFERENCES}

1. F. L. Riley, "Silicon Nitride and Related Materials," J. Am. Ceram. Soc., 83 [2] 245-65 (2000).

2. D. A. Gunn, "A Theoretical Evaluation of the Stability of Sialon Bonded Silicon Carbide in the Blast Furnace Environment," J. Eur. Ceram. Soc., 11 [1] 35-41 (1993).

3. F. F. Lange, "Silicon Nitride Polyphase Systems: Fabrication, Microstructure, and Properties," Int. Met. Rev., 25 [1] 1-20 (1980).

4. F. Lu, Q. Cai, L. Lu, Z. Zhang, and Z. Wang, "The Effects of Shock Activation on Sintering $\mathrm{Si}_{3} \mathrm{~N}_{4}$ Ceramics," J. Mater. Process. Technol., 147 [1] 90-3 (2004).

5. K. Kijima and S. Shirasaki, "Nitrogen Self-diffusion in Silicon Nitride," J. Chem. Phys., 65 [7] 2668-71 (1976).

6. P. Pettersson, Z. Shen, M. Johnsson, and M. Nygren, "Thermal Shock Properties of $\beta$-sialon Ceramics," J. Eur. Ceram. Soc., 22 [8] 1357-65 (2002).

7. M. Lewis, B. Powell, P. Drew, R. Lumby, B. North, and A. Taylor, "The Formation of Single-Phase Si-Al-ON Ceramics," J. Mater. Sci., 12 61-74 (1977).

8. J. S. Park, H. J. Lee, S. S. Ryu, S. M. Lee, H. J. Hwang, and Y. S. Han, "Optimization of Binder Burnout for Reaction Bonded $\mathrm{Si}_{3} \mathrm{~N}_{4}$ Substrate Fabrication by Tape Casting Method," J. Korean Ceram. Soc., 52 [6] 435-40 (2015).

9. A. R. Kheirandish, K. A. Nekouee, R. A. Khosroshahi, and N. Ehsani, "Self-Propagating High Temperature Synthesis of SiAlON," Int. J. Refract. Met. Hard Mater., 55 68-79 (2016).

10. K. Niihara, R. Morena, and D. P. H. Hasselman, "Evaluation of $\mathrm{K}_{\mathrm{IC}}$ of Brittle Solids by The Indentation Method with Low Crack-to-Indentation Ratios," J. Mater. Sci. Lett., 1 [1] 13-6 (1982).

11. H. R. Park, O. S. Lee, H. D. Park, and J. D. Lee, "Effect of Microstructures and Sintering Additives on the Mechanical Properties of $\mathrm{Si}_{3} \mathrm{~N}_{4}$," Korean J. Mater. Res., 2 [5] 33036 (1992).

12. S. T. Aruna and A. S. Mukasyan, "Combustion Synthesis and Nanomaterials," Curr. Opin. Solid State Mater. Sci., 12 [3] 44-50 (2008).

13. "Development of SiAlON Roll-Bearing for CGL Application," Report for KIMS-Funded Project (2013).

14. F. F. Lange, "High-Temperature Strength Behavior of HotPressed $\mathrm{Si}_{3} \mathrm{~N}_{4}$ : Evidence for Subcritical Crack Growth," J. Am. Ceram. Soc., 57 [2] 84-7 (1974).

15. G. Petzow and M. Herrmann, Silicon Nitride Ceramics, Structure and Bonding; Vol. 102, Springer-Verlag, Berlin, Heidelberg, 2002. 